Samuel Yáñez

Profesor de Filosofía en la Universidad Alberto Hurtado

\title{
Vida y religación (1)
}

Al cumplirse 50 años de la muerte de José Ortega y Gasset, este artículo busca mostrar de manera indicativa cómo las tesis básicas de la filosofía de Xavier Zubiri han de ser entendidas como desarrollos a partir de los logros del análisis orteguiano de la vida como realidad radical. Se hace especial hincapié en la noción de "fondo insobornable" que elaboró Ortega, como antecedente del concepto zubiriano de "religación”. Es sabido que esta noción le permitirá a Zubiri una consideración filosófica del problema de Dios y de las religiones. Las ideas de "fondo insobornable" y de "religación" apuntan a aquella dimensión radical de la vida humana donde palpita la pregunta por Dios y se abre la experiencia de una trascendencia en la más propia inmanencia.

Se cumplen 50 años de la muerte de Ortega. Pienso que la filosofía de Zubiri constituye en sí misma un buen homenaje a su memoria. En 1955 Zubiri publicaba un sentido recuerdo en un periódico español, donde se declaraba en gran medida hechura suya, refiriéndose a la influencia de Ortega en su propia filosofía. Así es. La filosofía de Zubiri es deudora de la filosofía de Ortega, en numerosos temas concretos y, más aún, en su misma dirección. En cierto modo, está instalada en su tradición y camino.

Sabido es que ambos, Ortega y Zubiri, recibieron el influjo filosófico de Husserl y Heidegger, influencia que contribuyó mucho a la orientación de sus propias búsquedas filosóficas. Esta influencia puede entenderse, en términos generales, en un doble sentido. Por una parte, la tarea filosófica es entendida como un esfuerzo por ir a las cosas mismas: no basta con una teoría del conocimiento científico, sino que es necesario abrir terreno a una nueva investigación ontológica. Tanto la filosofía de Husserl como la de Heidegger apuntaban a una renovada ontología. Por otro lado, esta tarea ontológica exige una descripción o análisis previo de lo dado: el camino de la ontología está precedido por una analítica, del fenómeno en el ámbito de la conciencia, en el caso de Husserl, del existente en el horizonte de la facticidad, en el caso de Heidegger.

(1) Una primera versión de este texto fue presentada en el Coloquio Internacional "Filosofía Iberoamericana. A cincuenta años de la muerte de Ortega", realizado en la Universidad Alberto Hurtado en el mes de mayo de 2005. 
Las aventuras filosóficas de Ortega y Zubiri se inscriben decididamente en estas sendas. Ambas tienen una intención metafísica. Entiendo aquí por metafísica, no primeramente un intento por ir más allá de lo físico, una ultrafísica, sino el esfuerzo de penetración en las cosas reales mismas, una transfísica que es al unísono una intrafísica. Por otra parte, ambas filosofías se despliegan desde una analítica con pretensiones originarias: la analítica de la vida como realidad radical, en el caso de Ortega, y el análisis de la aprehensión de realidad en Zubiri.

En el horizonte general de este parentesco - hay un aire de familia entre las filosofías de Husserl, Heidegger, Ortega y Zubiri-, en esta presentación pretendo conectar la noción orteguiana de vida con la idea zubiriana de religación. Ambos conceptos son fundamentales en las filosofías respectivas, sobre todo en lo que dice relación con el intento de una analítica primera. Además, ponerlos en relación patentiza en un caso concreto cómo la filosofía de Zubiri puede ser considerada un homenaje a la obra de Ortega. Homenaje que no consiste en mera repetición, por supuesto, sino en una asunción que sigue pensando lo asumido.

\section{LA VIDA COMO REALIDAD RADICAL (2)}

La filosofía de Ortega tiene su punto de partida en una analítica de la vida como realidad radical. Esta vida de la que aquí se habla es mi vida, donde el mi es solamente un agujero vacío en el cual hay que insertar el nombre de cada cual. Esta vida es, para cada cual, la realidad radical. Esto significa que la vida es lo dado sin más a cada cual, lo patente e indudable.

Al llamarla realidad radical no significa que sea la única, ni siquiera que sea la más elevada, respetable o sublime o suprema, sino simplemente que es la raíz -de aquí, radical- de todas las demás en el sentido de que estas, sean lo que fueren, tienen, para sernos realidad, que hacerse de algún modo presentes o, al menos, anunciarse en los ámbitos estremecidos de nuestra propia vida. Es, pues, esta realidad radical -mi vida- (...) el área o escenario ofrecido y abierto para que toda otra realidad en ella se manifieste (3).

Lo originariamente dado es la vida como realidad radical. Que se trate aquí de lo indudable remite al análisis que Ortega hace de la filosofía de Descartes. En el cogito cartesiano estaba ya encerrada esta tesis analítica: en toda actividad vital, el vivir de cada cual es indudable y radical. Solo que la concepción de Descartes de este hecho de todo hecho se sirve de la noción helénica de sustancia y de una interpretación subjetivista del faktum vital. Por ello, la filosofía de Descartes, a juicio de Ortega, desemboca en la res cogitans.

(2) Las referencias a los escritos de Ortega corresponden a la edición de sus Obras Completas en Revista de Occidente. En cada cita se indica el título del escrito, el tomo en que se encuentra y la página referida.

(3) El hombre y la gente, VII, 101. 
El pensamiento de Ortega ahonda en el análisis de la vida como realidad radical. La referencia a Descartes ya muestra que no se trata de la vida como un hecho meramente subjetivo. Para Ortega, yo soy yo y mi circunstancia. Vivir consiste en estar inmerso en una circunstancia, en "un cierto aquí e inexorable ahora" (4). Vivir es necesariamente un ocuparse con las cosas del mundo.

Nuestra vida, según esto, no es solo nuestra persona, sino que de ella forma parte nuestro mundo: ella -nuestra vida- consiste en que la persona se ocupa de las cosas o con ellas, y evidentemente lo que nuestra vida sea depende tanto de lo que sea nuestra persona como de lo que sea nuestro mundo. Ni nos es más próximo el uno que el otro término: no nos damos cuenta primero de nosotros y luego del contorno, sino que vivir es, desde luego, en su propia raíz, hallarse frente al mundo, sumergido en su tráfago, en sus problemas, en su trama azarosa. Pero también, viceversa: ese mundo (...) es inseparable de nosotros. Nacemos junto con él y son, vitalmente, persona y mundo como esas parejas de divinidades de la antigua Grecia y Roma que nacían y vivían juntas: los Dióscuros, por ejemplo, parejas de dioses que solían denominarse dii consentes, los dioses unánimes" (5).

Usando los términos de este texto orteguiano, persona y mundo resultan congéneres. En todo caso, la circunstancia es pensada por Ortega en sus diversos aspectos. Cabe destacar dos desde el punto de vista de una conexión con el pensamiento de Zubiri. Por un lado, la circunstancia es "absoluto fuera" (6) y, en cuanto tal, resulta un enigma. Pero por otra parte, la circunstancia es "un no-yo mío" (7). En cuanto mía, la circunstancia, según Ortega, se inscribe en el horizonte de mis posibilidades vitales. El mundo, entonces, aparece constituido radicalmente por asuntos o importancias.

Además de ser radical y transitiva, la vida posee también carácter ejecutivo y abierto: vivir consiste en un hacer, un tener que hacer sin saber en principio qué hay que hacer.

Esa vida que nos es dada, nos es dada vacía y el hombre tiene que írsela llenando, ocupándola. Estas son nuestras ocupaciones. Esto no acontece con la piedra, la planta, el animal. A ellos les es dado su ser ya prefijado y resuelto. A la piedra, cuando empieza a ser no le es dada solo su existencia, sino que le es prefijado de antemano su comportamiento -a saber, pesar, gravitar hacia el centro de la tierra. Parejamente al animal le es dado el repertorio de su conducta, que va, sin su intervención, gobernada por sus instintos. Pero al hombre le es dada la forzosidad de tener que estar haciendo siempre algo, so pena de sucumbir, mas no le es, de antemano y de una vez para siempre, presente lo que tiene que hacer. Porque lo más extraño y azorante de esa circunstancia o

\footnotetext{
(4) En torno a Galileo, V, 23.

(5) Unas lecciones de metafísica, 38.

(6) Goethe desde dentro, IV, 426.

(7) El hombre y la gente, VII, 159.
} 
mundo en que tenemos que vivir consiste en que nos presenta siempre, dentro de su círculo y horizonte inexorable, una variedad de posibilidades para nuestra acción" (8).

El ser radical del vivir, pues, estriba en el hacer. Y lo que propia y primariamente se va haciendo es la propia vida. En su actualidad, la vida es faena y tarea abierta, forzosidad de resolver el problema de sí misma. La vida es actividad radical, el acto de todo acto, hacer esencial. El carácter abierto de esta vida le permite insertar a Ortega, por su parte, el tema de la elección ante las posibilidades vitales y la referencia a la fantasía creadora. Vivir es optar e inventar: se trata de la vida del "animal fantástico" (9) que es cada uno.

Ahora bien, dice Ortega, nos encontramos viviendo, es decir, teniendo que hacer sin saber qué hacer. Por este no saber, la realidad vital se nos presenta como naufragio e inseguridad radicales. Desde esta perspectiva, la conciencia de sentirnos perdidos nos patentiza una dimensión radical de la verdad de la vida. Desde esta perplejidad e ignorancia constitutivas del vivir se eleva un no menos constitutivo afán de justificación.

El hombre es el único viviente que para vivir necesita darse razones de existir. La cosa es increíble, pero indubitable, pero inexorable. La vida humana necesita -quiera o no- justificarse ante sus propios ojos. Solo podemos vivir apoyados en ciertas ideas sobre nosotros mismos (10).

Esta justificación implica necesariamente una interpretación intelectiva de lo que es la vida, con todos sus ingredientes. Y dado el carácter ejecutivo del vivir, el saber es originariamente un saber a qué atenerse respecto de la circunstancia. La idea, en su dimensión vital radical, es una respuesta a la experiencia de la vida como radical problema de sí misma. La idea viva, originaria, es la que brota de un naufragio.

En su ensayo titulado Ni vitalismo ni racionalismo de 1924, Ortega defendía esta concepción: lo suyo no es una filosofía vitalista sin más, sino una filosofía raciovitalista, entendiendo por razón en sentido lato esta justificación originaria y lo que de ella se deriva. Vivir da que pensar; más aún: vivir exige pensar. A su juicio, uno de los dramas heredados del siglo XIX europeo radica, justamente, en esa separación e incluso contraposición entre el mundo de la vida y el mundo de la cultura. Porque, en términos originarios, cultura es esto.

El pobre humano, sintiendo que se sumerge en el abismo, agita los brazos para mantenerse a flote. Esa agitación de los brazos con que reacciona ante su propia perdición, es la cultura -un movimiento natatorio (11).

\footnotetext{
(8) Ibídem, 102-103.

(9) Ibídem, 253.

(10) Los 'nuevos' Estados Unidos, IV, 359.

(11) Goethe desde dentro, IV, 397.
} 
Desde otra perspectiva, la vida como realidad radical es también radical soledad.

Entre todos esos caracteres de la realidad radical o vida que he enunciado y que son una mínima parte de los que fuera menester describir para dar una idea algo adecuada de ella, el que me interesa ahora subrayar es el que hace notar la gran perogrullada: que la vida es intransferible y que cada cual tiene que vivirse la suya; que nadie puede sustituirle en la faena de vivir; que el dolor de muelas que siente tiene que dolerle a él y no puede traspasar a otro ni un pedazo de ese dolor; que ningún otro puede elegir ni decidir por delegación suya lo que va a hacer, lo que va a ser; que nadie puede reemplazarle ni subrogarse a él en sentir y querer; en fin, que no puede encargar al prójimo de pensar en lugar suyo los pensamientos que necesita pensar para orientarse en el mundo -en el mundo de las cosas y en el mundo de los hombres- y así acertar en su conducta; (...) y como esto acontece con mis decisiones, voluntades, sentires, tenemos que la vida humana sensu stricto por ser intransferible resulta que es esencialmente soledad, radical soledad (12).

Esto no significa, empero, una soledad solipcista, encerrada en sí misma y excluyente de toda otra vida. Desde este fondo de radical soledad asciende un no menos radical afán de compañía. Aunque siempre, en el fondo, estamos solos, pues hay una porción radical de la vida de cada cual que es "incomunicable" (13). La apertura social, por su parte, se concreta en sociedad, cuyo hecho por excelencia es el uso o costumbre, y también en comunidad, entendida por Ortega como ámbito de encuentro entre tú y yo.

Otro carácter esencial de la vida como realidad radical es su historicidad. " $L a$ vida es un gerundio y no un participio: un faciendum y no un factum" (14). En cuanto histórica, la vida es una cadena de sucesivas experiencias. Vivir es haber pasado peligros. Esto significa que vivir es hacerlo necesariamente en "un cierto aquí $e$ insustituible ahora" (15). Toda forma de vida está adscrita a una fecha determinada. Y ese aquí y ahora viene de momentos anteriores y abre posibilidades siempre limitadas. Por ello, concluye Ortega, la historia es un sistema, el sistema de las experiencias vitales. Sabido es que la conjunción de los caracteres social e histórico de la vida como realidad radical permite a Ortega elaborar su teoría de las generaciones.

\section{EL PROBLEMA DE FONDO}

La idea de vocación ocupa un lugar central en la analítica orteguiana de la vida como realidad radical, a tal punto que puede afirmarse que es su luz la que hace posible una plena comprensión de lo que el pensador español entiende por vida. La

(12) El hombre y la gente, VII, 105.

(13) A una edición de sus obras, VI, 345.

(14) Historia como sistema, VI, 32-33.

(15) A una edición de sus obras, VI, 347-348. 
vocación es el ingrediente más extraño y misterioso de la vida, constituye su raíz más profunda y propia (16). Se trata del auténtico y verdadero ser de la vida de cada cual (17). El asedio de Ortega a esta raíz ontológica es polifacético y complejo. Tal vez, pueda darse cuenta de ello a partir de algunas nociones usadas por el mismo Ortega.

El impulso vocacional brota desde un fondo insobornable.

Es inevitable: hacia los treinta años, en medio de los fuegos juveniles que perduran, aparece la primera línea de nieve y congelación sobre las cimas de nuestra alma. Llegan a nuestra experiencia las primeras noticias directas del frío moral. Un frío que no viene de fuera, sino que nace de lo más íntimo y desde allí envía al resto del espíritu un efecto extraño, que más que nada se parece a la impresión producida por una mirada quieta y fija sobre nosotros. No es aún tristeza, ni es amargura, ni es melancolía lo que suscitan los treinta años: es más bien un imperativo de verdad y una como repugnancia hacia lo fantasmagórico. Por esto, es la edad en que dejamos de ser lo que nos han enseñado, lo que hemos recibido en la familia, en la escuela, en el lugar común de nuestra sociedad. Nuestra voluntad gira en redondo. Hasta entonces habíamos querido ser lo que creíamos mejor: el héroe que la historia ensalza, el personaje romántico que la novela idealiza, el justo que la moral recibida nos propone como norma. Ahora, de pronto, sin dejar de creer que todas esas cosas son tal vez las mejores, empezamos a querer ser nosotros mismos, a veces con plena conciencia de nuestros radicales defectos. Queremos ser, ante todo, la verdad de lo que somos, y muy especialmente nos resolvemos a poner bien en claro qué es lo que sentimos del mundo. Rompiendo entonces sin conmiseración la costra de opiniones y pensamientos recibidos, interpelamos a cierto fondo insobornable que hay en nosotros. Insobornable, no solo para el dinero o el halago, sino hasta para la ética, la ciencia y la razón. La misma convicción científica (...) toma un cariz superficial si se la compara con las afirmaciones y negaciones que inexorablemente ejecuta ese fondo sustancial (18).

La raíz de la realidad radical que es la vida de cada cual es un fondo de afirmaciones y negaciones inexorables. Tal fondo es anterior a la libertad (19) y constituye la base de nuestra singular personalidad. Por ser lo más profundo, este fondo incorruptible suele ser ignoto, incluso para uno mismo. Conocerlo supone una buena dosis de valiente decisión, entrenamiento, silencio y soledad (20). Más que algo poseído en la vida de cada cual, es este fondo el que tiene, sostiene y lleva la vida -lo quiera o no lo quiera cada cual. Es posible negar la conciencia de este fondo, de diversas maneras, pero él -inconmovible como mirada quieta y fija- permanece allá abajo, sentenciando

(16) En torno a Galileo, V, 138; Introducción a Velásquez, VIII, 566.

(17) Goethe desde dentro, IV, 400; Meditación de la técnica, V, 338.

(18) Ideas sobre Pío Baroja, II, 74-75.

(19) No ser hombre de partido, IV, 77.

(20) Meditación de la técnica, V, 331, 341, 352. 
y susurrando su palabra enérgica y a la vez tenue. El fondo parece tener voz. Dicha voz incita a efectuar ciertos quehaceres y buscar ciertos objetos en el mundo. Pero estos quehaceres y objetos aún no son conocidos, ni siquiera es seguro que sean encontrados. Sin embargo, el fondo insobornable pareciera ya conocerlos de antemano. Si bien la conciencia de vivir como individuos singularísimos, únicos e irrepetibles, nace en el tiempo conjuntamente con la conciencia de nuestro fondo inexorable, sin embargo se experimenta a este último como anterior al propio vivir, como si fuera él quien impulsara la vida. Ortega lo dice con una hermosa expresión: el fondo insobornable es "el tiempo a la espalda del tiempo" (21). Además, si este fondo parece adelantarse al porvenir, entonces debe ser comprendido como el pozo de las promesas y posibilidades. Mas no todas las posibilidades dan lo mismo. Entre las diversas posibilidades que siempre se ofrecen en la vida, el fondo sotto voce impele a elegir una, aquella que se yergue exigiendo el respeto de sus peculiares prerrogativas. Todas las posibilidades pueden ser, pero hay una que tendría que ser. En suma, el fondo se muestra como base, como voz y raíz de toda vocación, como fuente de posibilidades y como imperativo.

Llama también la atención de Ortega otro aspecto de este fondo insobornable: es la fuente generatriz de las preferencias y desdenes de la vida. Se trata aquí del sistema más hondo de preferencias, de los afanes íntimos que cargan la vida de cada uno en sus brazos, orientando la atención y la acción (22) Desde este punto de vista, la vida aparece como un ensayo de apoteosis de lo que se estima mejor (23). Este acto radical de estimación modela el carácter de la vocación.

Entre los amores humanos, Ortega distingue dos clases específicas. Se trata de dos rangos diversos por su profundidad. Por un lado, están aquellos amores que suponen la vida efectiva, esto es, que suponen el hecho de haber resuelto ser el que en verdad se es. Porque ya se es, este ser hace amar lo que efectivamente se ama. Por ejemplo, pertenecen a este grupo el amor a tal persona, a la patria, al deporte, a la carpintería. Pero estos amores no agotan el conjunto de las predilecciones. Hay una de ellas que queda fuera: justamente, como dice Ortega, "el deseo de los deseos" (24), la condición intrínseca de los otros amores. Es el "deseo de sí mismo" (25). La predilección se dirige, antes que a las cosas del mundo, a una vida concretísima posible, aquella que realiza la propia vocación. Se trata aquí de una anterioridad no temporal.

¿Qué es la vocación, entonces? Lo que se tiene que ser. Y como el ser de la vida es ejecutivo, lo que hay que ser es en verdad lo que hay que hacer. De este modo, la vocación para Ortega resulta ser un proyecto de quehaceres, un plan de campaña para la propia vida.

Usted no es cosa ninguna, es simplemente el que tiene que vivir con las cosas, entre las cosas, el que tiene que vivir no una vida cualquiera, sino una vida determinada. No hay un vivir abstracto. Vida significa la inexorable forzosidad

(21) Introducción a Velásquez, VIII, 565.

(22) El tema de nuestro tiempo, III, 151; La metafísica y Leibniz, III, 599-600.

(23) Kant. Reflexiones de centenario, IV, 42.

(24) Meditación de la técnica, V, 344.

(25) Ídem. 
de realizar el proyecto de existencia que cada cual es. Este proyecto en que consiste el yo no es una idea o plan ideado por el hombre y libremente elegido. Es anterior, en el sentido de independiente, a todas las ideas que su inteligencia forme, a todas las decisiones de su voluntad. Más aún, de ordinario no tenemos de él sino un vago conocimiento. Sin embargo, es nuestro auténtico ser, es nuestro destino. Nuestra voluntad es libre para realizar o no ese proyecto vital que últimamente somos, pero no puede corregirlo, cambiarlo, prescindir de él o sutituirlo. Somos indeleblemente ese único personaje programático que necesita realizarse. El mundo en torno o nuestro propio carácter nos facilitan o dificultan más o menos esa realización. La vida es constitutivamente un drama, porque es la lucha frenética con las cosas y aun con nuestro carácter por conseguir ser de hecho el que somos en proyecto (26).

Para Ortega, pues, la vocación es proyecto concreto de quehaceres, potencial de actos, programa determinadísimo de existencia, personaje íntimo que brega por realizarse, programa vital ofrecido a la libertad, perfil de conducta, imperativo de ocupación originaria e incoercible (27). En suma, vocación es misión y tarea. Ella comprehende todos los órdenes e instantes de la vida. Como decía Píndaro: llega a ser el que eres. Desde este sí mismo más radical todo adquiere su adecuada colocación. Se trata de un destino.

Los antiguos usaban confusamente de un término cuyo verdadero significado coincide con ese que he llamado proyecto vital: hablaban del destino y creían que consistía en las cosas que a una persona le pasaban. Pronto se advierte que una misma aventura puede acontecer a dos hombres y, sin embargo, tener en la vida de uno y otro valores distintos y hasta opuestos, ser para uno una delicia y para otro un desastre. Lo que nos pasa, pues, depende para sus efectos vitales, que es lo decisivo, de quién seamos cada uno. Nuestro ser radical, el proyecto de existencia en que consistimos, califica y da uno y otro valor a cuanto nos rodea. De donde resulta que el verdadero destino es nuestro ser mismo. Lo que fundamentalmente nos pasa es ser el que somos (28).

En cuanto destino, la vocación revela el ser finito de la vida como realidad radical. No es una limitación foránea, venida de fuera, sino que la vida de cada cual es limitación constitutiva. Como dice Ortega, "lo que nos falta, nos sostiene" (29).

Recapitulemos brevemente lo desarrollado hasta aquí. El análisis de Ortega se mueve en el nivel de la vida, $m i$ vida y $t u$ vida, comprendida como la realidad radical. No parece decir Ortega qué hay que entender aquí por realidad. Esta vida tiene diversos caracteres constitutivos: transitividad, ejecutividad, apertura, inseguridad y afán de justificación, soledad y afán de compañía, historicidad. Ahora bien,

(26) Goethe desde dentro, IV, 400.

(27) Ideas sobre Pío Baroja, II, 80; No ser hombre de partido, IV, 77; La elección en amor, V, 608; Goethe desde dentro, IV, 406; Origen y epílogo de la filosofía, IX, 357.

(28) No ser hombre de partido, IV, 77.

(29) Vicisitudes de las ciencias, IV, 66. 
al sumergir la mirada en las raíces de esta realidad ya radical, se encuentra uno con la vocación. Esta es el núcleo constitutivo de lo que cada cual es. Y consiste en ser un programa de quehaceres, un destino. Finalmente, la raíz última de esta raíz de raíces la encuentra Ortega en aquel fondo insobornable, voz, base y origen de toda vocación, fuente de las posibilidades, imperativo inexorable, sistema fontanal de preferencias y desdenes.

\section{LA RELIGACIÓN}

Pienso que la filosofía de Zubiri cuenta con los logros alcanzados por el pensamiento de Ortega. Y que, desde esta altura, es posible ver cómo se va desplegando la reflexión de Zubiri, hasta ofrecer sus frutos más peculiares: la idea de realidad como formalidad, la idea del sentir intelectivo y la idea de religación. Zubiri adhirió a su modo a numerosas tesis orteguianas. Pero era necesario seguir pensando filosóficamente el problema de la vida como realidad radical. Un ejemplo puede ilustrar esta necesidad.

Ortega sostiene que "la vida es en sí misma y siempre un naufragio" (30). Por eso, desde ella surge, con no menor radicalidad, un afán de justificación (31). Siguiendo esta línea de pensamiento, Ortega concluye que la realidad es en sí misma enigmática y que el viviente humano interpreta dicho enigma con la materia intangible de las ideas. Estas son creaciones irreales (32). Justificar la vida es peregrinar desde el mudo lenguaje del ser al expreso lenguaje del decir (33). Ahora bien, esta manera de concebir la relación originaria entre la ignorancia radical -naufragio le llama Ortega- y la vida intelectiva, ¿no está aún necesitada de mayor precisión filosófica?

Patentemente, estas expresiones de Ortega no hay que interpretarlas en sentido kantiano. Si así se hiciera, se tendría en el pensamiento de Ortega la afirmación, tanto de un dualismo originario entre naufragio y justificación (las ideas son creaciones irreales), como de una ceguera originaria (la realidad permanece constitutivamente enigmática). Si bien Ortega pasó años de formación en el ambiente neokantiano de Marburgo, él mismo sostiene expresamente haber abandonado el encierro kantiano en que estuvo. Y es así efectivamente. Mas, ¿cómo pensar suficientemente desde una inspiración unitaria y radical el acto originario de aprehensión de realidad? Porque si vivir es experimentar la realidad enigmática al modo de un naufragio, entonces la realidad está ya aprehendida. No hay ceguera primordial, por tanto.

Por otra parte, no es que la angustia del naufragio lleve a la necesidad de la justificación: concebir las cosas así significa radicar la positividad intelectiva en la negatividad vital. ¿No será, más bien, que la realidad ya aprehendida es la que da que pensar? Si es así, entonces no es la vida la que exige pensar, sino la realidad la que nos impele a vivir pensando. La positividad real es la base de toda positividad.

(30) Goethe desde dentro, IV, 397.

(31) Meditaciones del Quijote, I, 357, 360; El arte en presente y en pretérito, III, 422.

(32) La deshumanización del arte, III, 376.

(33) Origen y epílogo de la filosofía, IX, 372. 
Radicar la justificación en el naufragio puede representar, de algún modo, una pervivencia del horizonte creacional de la filosofía europea medieval y moderna. En efecto, en ese horizonte, el ens creatum es una nada de ser llegada al ser. Por supuesto, se trata de una pervivencia del horizonte de la nihilidad en un contexto filosófico contemporáneo, que no cuenta ya con aquella positividad creadora originaria de la experiencia religiosa cristiana.

Por el claro abierto por cuestiones como esta se interna la reflexión de Zubiri. En la raíz de la vida, que es la realidad radical, hay una aprehensión de realidad. Yo soy yo y mi circunstancia. Y esta circunstancia es realidad enigmática y no-yo mío. En cuanto no-yo, es alteridad; en tanto mía, está aprehendida. El vivir, por tanto, aloja un acto de aprehensión de alteridad. La raíz de la vida de cada cual es un estar aprehensivo. No se trata de un estar pasivo, sino de un activo estar. Y de un estar real, en la medida que lo aprehendido lo es.

La noción radical de realidad, entonces, no es la de lo que existe en sí, fuera de la mente, ni tampoco la de lo que existe para mí, al modo de algo puesto. La idea originaria de realidad es la de alteridad dada en esa aprehensión que está a la raíz del vivir de cada cual. ¿En qué consiste dicha alteridad? Sus contenidos son muy diversos. Pero la alteridad no consiste formalmente en sus contenidos, sino justamente en un modo de quedar los contenidos. ¿Cuál es ese modo? La alteridad de realidad consiste en quedar de tal modo en la aprehensión, cualquiera sea el contenido concreto, que este queda como fundando el propio acto aprehensor. Quedar como real es quedar como siendo formalmente anterior a la aprehensión misma. Zubiri llama formalidad al modo de quedar. De esta manera, realidad es radicalmente una formalidad.

Este es el primer fruto que se alcanza siguiendo a Zubiri desde Ortega. Realidad es formalidad. Como tal, ella ya está accedida originariamente en el vivir. Más aún, vivir es un drama que se desarrolla ab initio en el elemento de esta formalidad de alteridad. Ortega no negaba que la vida como realidad radical estuviese implantada en la realidad. En efecto, llamaba a la vida justamente realidad radical. Pero Zubiri ayuda a precisar filosóficamente el asunto.

Ahora bien, Ortega decía que la circunstancia es un no-yo mío. Hay un polo del mí en la raíz del vivir. ¿Cómo conceptuar este polo aprehensor de realidad? Zubiri piensa que esta raíz activa y constitutiva de todo acto vital es la impresión de realidad. Como lo aprehendido es realidad, es decir, aquella formalidad consistente en un quedar en la aprehensión en anterioridad formal respecto del acto aprehensivo, entonces el acto aprehensor es radicalmente un acto de impresión. Se trata de un acto pasivo. Una impresión supone la posibilidad de ser impresionado. El acto impresivo, entonces, debe ser llamado acto sentiente, pues sensibilidad es precisamente impresividad. El acto aprehensor es un acto sentiente. Desde esta perspectiva, se descubre al viviente humano, en su raíz misma, como el animal impresionado por la realidad.

Ahora bien, lo que se aprehende impresivamente es la realidad como formalidad. La impresión de realidad, por tanto, implica la actualización de dicha formalidad en la aprehensión. Recogiendo la tradición terminológica de la historia de la filosofía, parece haber buenas razones para denominar intelección a dicha actualización de realidad. Inteligir es esto, entonces: mera actualización de lo real en la 
aprehensión. Haciendo esto, Zubiri da a luz una nueva idea del acto intelectivo. De este modo, el acto radical de impresión de realidad aparece como un acto de sentir intelectivo, o de inteligir sentiente. No se trata aquí de dos actos distintos que confluyen sintéticamente (sentir e inteligir), sino de un acto estructural y formalmente unitario. Como señala Zubiri, en este caso sentir es un modo de inteligir, e inteligir un modo de sentir.

He aquí un segundo fruto alcanzado por Zubiri: en su raíz, la actividad vital consiste en impresión de realidad y, por tanto, en un activo estar, que es un sentir intelectivo o un inteligir sentiente. Al vivir, el viviente humano está ya implantado en la realidad por su inteligir. Pero la realidad es aprehendida en impresión y, por tanto, de modo no plenario en toda su riqueza y profundidad. En la impresión de realidad se encuentra la raíz, entonces, de todo logos y razón, actividades ambas, intelectivas y sentientes a la vez, que se mueven en el elemento real intentando penetrar más hondamente en él. Es la aprehensión primordial de realidad la que lleva a vivir pensando. Y como en esta aprehensión, realidad es modo de quedar en anterioridad formal, resulta que es la realidad misma la que en última instancia impele a cada cual a vivir pensando.

En su raíz, la vida de cada cual es aprehensión de realidad. Cabe todavía, empero, otra pregunta: ¿hay algo más al fondo? Zubiri, al igual que Ortega, piensa que sí: está el fondo insobornable. El caso de una percepción simple puede ayudar a desarrollar el punto.

Escucho un sonido. Lo aprehendo como real. ¿Qué me ha sido dado? La cosa real, que es el sonido. Pero puedo distinguir analíticamente en él su aspecto de cosa, por supuesto real, y su aspecto de real. Su realidad como formalidad, es decir, como modo de quedar, le pertenece intrínsecamente en cuanto cosa, por así decirlo. Pero no se agota esta, su realidad, en el hecho de ser suya. Siendo $s u$ realidad, es sin embargo más que la cosa real. Lo aprehendido entonces en la percepción es la cosa real y, en ella, la realidad como tal, ese modo de quedar que es más. Al oír el sonido real, por tanto, he oído la realidad en forma de sonido.

Ahora bien, esta realidad oída se me da como base de mi actividad vital. En efecto, la realidad sonante me abre diversas posibilidades: taparme el oído, resbalar indiferentemente sobre el sonido, aguzar mi atención para gozar la melodía, y otras más. Se trata de una diversidad de posibilidades, entre las cuales imperativamente tengo que optar por alguna. La realidad oída resulta de algún modo fuente radical, posibilitante e impelente de mi actividad vital. Por decirlo así, la aprehensión de realidad se me revela, no como un acto de posesión de mi parte, sino más bien como la actividad de ser poseído por la misma realidad, que me tiene, me proyecta y me empuja.

Ahora bien, la realidad sonante, decía, en cuanto realidad, no se agota en este sonido real, en cuanto tal sonido. Es más que él. Zubiri dice: la realidad tiene dominancia sobre la cosa real. Por otra parte, la misma realidad sonante, también en cuanto realidad, se ha apoderado de mi vivir en la aprehensión, al modo de un suelo posibilitante e impelente. De este modo, la realidad también tiene dominancia sobre mi vivir. Pues bien, a la dominancia de la realidad en tanto realidad, Zubiri la denomina con el término poder. El poder es en Zubiri poder de realidad. Y este poder de realidad entonces se manifiesta como ingrediente constitutivo en mi per- 
cepción. Vivir, estar en la realidad aprehensivamente, consiste formalmente en estar religado al poder de la realidad. La vida de cada cual muestra así su raíz constitutiva nuclear: la religación al poder de realidad. Es el tercer fruto que se alcanza al recorrer la filosofía de Zubiri partiendo desde la idea orteguiana de la vida como realidad radical.

En cuanto posibilitante e impelente, el poder de la realidad está intrínsecamente unido al problema de los proyectos vitales. Para Zubiri también se trata de una voz y, por tanto, dice relación con la vocación. Pero Zubiri no desarrolla más el asunto por esta vertiente. Le interesa otro aspecto. La religación al poder de la realidad deja planteado el problema del fundamento de este poder. Por ello, el descubrimiento de la religación lleva a Zubiri a embarcarse en una justificación intelectiva de la realidad de Dios y en una reflexión sobre el despliegue de la religación en experiencia religiosa. Esta vía no la recorrió Ortega. Aunque un pasaje suyo invitaba a hacerlo. En efecto, decía, la vida es "texto eterno donde Dios da sus voces" (34).

\section{RESUMEN}

Al cumplirse 50 años de la muerte de José Ortega y Gasset, este artículo busca mostrar de manera indicativa cómo las tesis básicas de la filosofía de Xavier Zubiri han de ser entendidas como desarrollos a partir de los logros del análisis orteguiano de la vida como realidad radical. Se hace especial hincapié en la noción de "fondo insobornable" que elaboró Ortega, como antecedente del concepto zubiriano de "religación". Es sabido que esta noción le permitirá a Zubiri una consideración filosófica del problema de Dios y de las religiones. Las ideas de "fondo insobornable" y de "religación" apuntan a aquella dimensión radical de la vida humana donde palpita la pregunta por Dios y se abre la experiencia de una trascendencia en la más propia inmanencia.

\section{ABSTRACT}

On the 50th anniversary of the death of José Ortega y Gasset, this article seeks to show in an indicative manner how the basic theses of Xavier Zubiri's philosophies have to be understood: as developments that begin with the achievements of Ortega's analysis of life as a radical reality. Special emphasis is made on the notion of the incorruptible foundation that Ortega elaborated, as an antecedent to Zubiri's concept of "religación" (binding). As is known, this notion will permit Zubiri to take on a philosophical consideration of the problem of God and of religions. The ideas of fondo insobornable and of religación point towards that radical dimension of human life where the question about God palpitates and opens one to the experience of a transcendency in its most inherent immanence. 